\title{
A NOTE ON THE RECORDING OF EPIDURAL NEGATIVE PRESSURE
}

\author{
José E. Usubiaga, M.D., Frank Moya, M.D., AND LiIia E. Usubiaga, M.D.
}

ThE SIGNIFicance of the negative pressure found within the epidural space has been a point of considerable argument. A physiological parameter to some authors or an artifact created by the blunt edge of the advancing needle to others (for references see Bromage ${ }^{1}$ ), negative epidural pressure has been intermittently monitored with rather crude instruments; to our knowledge no device for recording this parameter has been made. Therefore, in order to gain further insight into this subject we continuously recorded the resting pressure of the epidural space in a group of sixteen adult male patients undergoing epidural blockade.

\section{METHOD}

The method has been previously described. ${ }^{2}$ Briefly, each subject was placed in the lateral recumbent flexed position and instructed to breathe as normally as possible. A \# 17 gauge Tuohy needle was inserted at cervical 6-7, thoracic 8-9, lumbar 4-5, or the sacral level of the spine, and connected by a polyethylene tube filled with saline to a Statham transducer and a direct ink recorder. The epidural space was recognized by the change in resistance encountered after piercing either the ligamentum flavum or the sacro-coccygeal membrane. Epidural pressure was recorded for three to ten minutes.

\section{RESULTS}

Except in the sacral canal, a negative epidural pressure was always found. Negative pressure was magnified by increasing and reduced by decreasing the flexion of the spine; it even became positive when the patient straightened his back. Depending on the position of the needle, two different components of negative pressure could be recognized (Fig. 1). A basal value, seen when entering the epidural space, ranged from -1 to $-7 \mathrm{~cm} . \mathrm{H}_{2} \mathrm{O}$. It remained stable providing the patient was well relaxed. An artefactual component up to $-30 \mathrm{~cm}$. $\mathrm{H}_{2} \mathrm{O}$ appeared when the needle was further advanced against the dural sac. It disappeared when the fingers of the operator released the needle.

Simultaneous punctures at different levels of the spine showed that negative pressure was not uniform along the epidural space. The highest values were found in the thoracic region, and the lowest appeared in the lumbar zone. It was also observed that the injection of $10 \mathrm{cc}$. of anaesthetic solution through one needle did not modify the negative pressure in other epidural regions, providing the needles were separated by a distance of eight to ten vertebrae.

\footnotetext{
-Department of Anesthesiology, University of Miami School of Medicine and Jackson Memorial Hospital, Miami, Florida.
} 


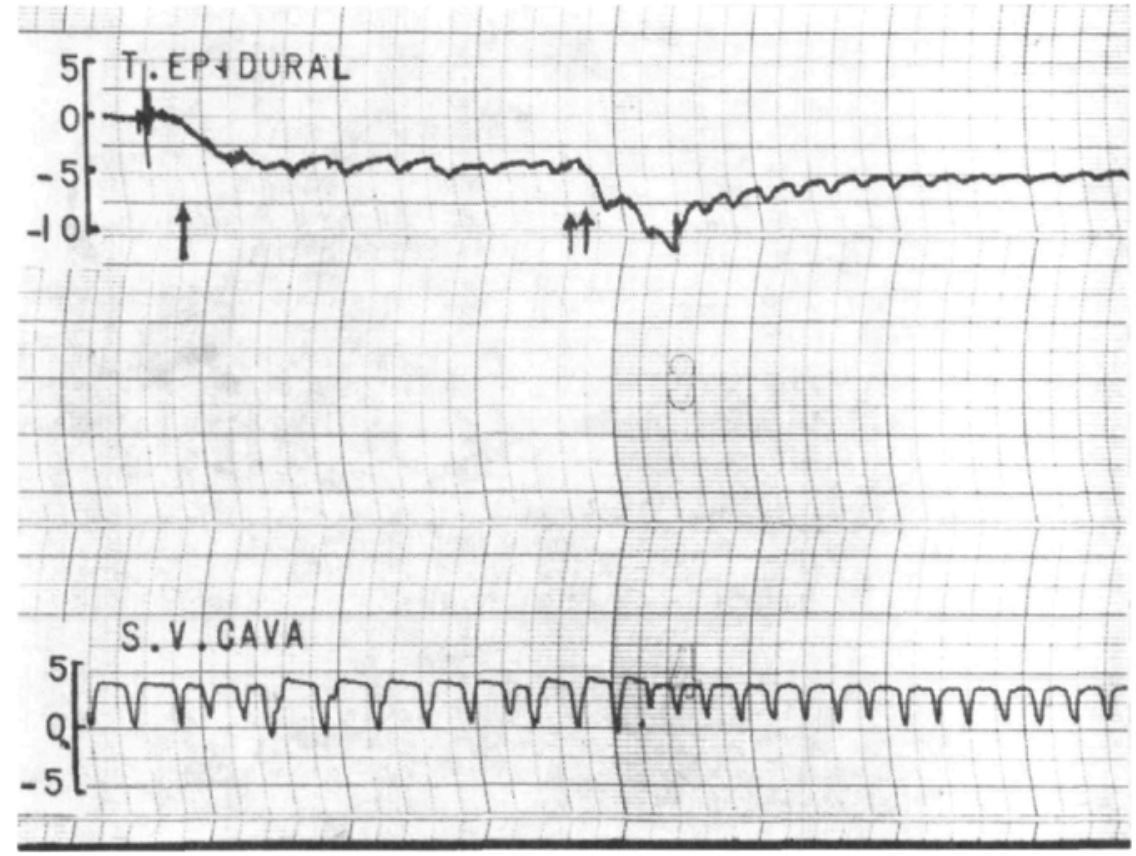

Frgure 1. Top line: Epidural space pressure tracing at thoracic 8-9 interspace. Bottom line: Superior vena cava pressure tracing. At the first arrow the needle enters the epidural space and a negative pressure of -3 to $-5 \mathrm{~cm} . \mathrm{H}_{2} \mathrm{O}$ is found. Epidural pressure tracing shows respiratory oscillations synchronous with pressure changes in the superior vena cava tracing. At the second arrow the needle is introduced further and a greater negative pressure appears. After releasing the needle, the epidural space pressure returns to fower negative levels.

In eight individuals, the epidural pressure tracing oscillated during normal respiration and also oscillated synchronously with arterial beats. In the cervicothoracic area, negative pressure was increased during inspiration and decreased during expiration (4 cm. $\mathrm{H}_{2} \mathrm{O}$ range). By contrast, in the lumbar area, an opposite cycling was seen ( $2 \mathrm{~cm}$. $\mathrm{H}_{2} \mathrm{O}$ range). In all cases, however, epidural pressure remained negative throughout both phases of the respiratory cycle.

\section{COMMENTS}

It appears from the present results that negative pressure is produced neither by the needle nor, primarily, by transmission of subatmospheric intrathoracic pressure to the epidural space. Rather, it depends on the degree of ventral flexion of the spine. One possible mechanism could be the unfolding of the ligamenta flava produced by separation of the adjacent laminae during flexion, thus increasing the size of the epidural space. ${ }^{3}$

Some of the factors which modify negative pressure are the head-up position, cough, and Valsalva, Queckendsted, and abdominal wall compression mancuvres. ${ }^{4}$ Generally speaking, any rise in central venous or cerebrospinal fluid pressure can reduce or abolish negative pressure. Basal negative pressure changes during the 
respiratory cycle. There is general agreement that negative pressure increases during inspiration by the transmission of the negative intrathoracic pressure through the intervertebral foramina. ${ }^{5}$ For that reason it has been recommended that the epidural space be entered during the inspiratory phase. Some years ago, however, Bromage performed a series of lumbar epidural punctures in seated patients, advancing the needle only during expiration. Surprisingly he found negative pressure in ten out of sixteen subjects. ${ }^{6}$ It would therefore be an oversimplification to ascribe all the effects of respiration to a direct transforaminal transmission of pressures. We believe respiratory changes are transmitted also in other ways, via venous and cerebrospinal fluid displacements. ${ }^{4}$ In the thoracic epidural space all changes are in phase, therefore negative pressure is exaggerated during inspiration. At the lumbar level, however, pressure in the epidural veins follows the intra-abdominal pressure pattern which opposes intrathoracic changes. It follows that the increase in lumbar epidural pressure during expiration could explain Bromage's paradoxical results.

\section{SUMMARY}

A recording of the negative pressure of the epidural space is presented. Two components can be demonstrated: a basal subatmospheric pressure exaggerated by flexion of the spine and an artefactual value produced by further advancing the needle. Negative pressure is a segmental phenomenon since it can persist in one epidural area despite its disappearance in other remote zones.

During normal respiration two opposite cyclings of basal epidural pressure were observed, the pressure changes being more marked at the thoracic level. It is suggested that to enter the cervicothoracic epidural space, the needle should be advanced during inspiration, whereas in the lumbar region adequate position of the patient is far more important than the phase of the respiratory cycle.

\section{RÉsUMÉ}

On présente un enregistrement de la pression négative de l'espace épidural. On peut démontrer deux composantes, une pression de base sous-atmosphérique augmentée par la flexion de la colonne et une valeur artificielle provoquée en poussant l'aiguille davantage. La pression négative est un phénomène segmentaire, car elle peut persister dans une zone épidurale et disparaître dans d'autres zônes à distance.

Durant la respiration normale, on a observé deux cycles opposés de pression épidurale de base; les variations de pression ont été plus prononcées au niveau du thorax. On croit que, pour pénétrer dans l'espace épidural cervico-thoracique, l'aiguille devrait être poussée durant l'inspiration; par contre, dans la région lombaire, la position du malade est bien plus importante que la phase du cycle respiratoire.

\section{REFERENCES}

1. Bromace, P. R. Lumbar Epidural Anesthesia. Baltimore: Williams and Wilkins (1954), p. 37. 
2. Usuriaga, J. E.; Wismssco, J. A.; \& Usubiaga, L. E. Epidural Pressure and Its Relationship with the Spread of Anesthetic Solution into the Epidural Space. Anesth. \& Analg. (In press.)

3. UsubiagA, J. E. Peridural Cervicotoracica. Rol del ligamento amarillo en anesthesia peridural. IX Congr. Arg. de Anestesiol. Buenos Aires (1963).

4. UsubiagA, J. E. \& MoYA, F. Effect of Thoracic and Abdominal Pressure Changes on the Epidural Space Pressure. (In preparation.)

5. Macintose, R. R. \& Mushen, W. W. Observations on the Epidural Space. Anaesthesia. 2: 100 (1947).

6. Bromage, P. R. Op. cit. 41. 